\title{
Health promotion in the trucking setting: Understanding Dutch truck drivers' road to healthy lifestyle changes
}

\author{
Anniek Boeijinga ${ }^{\mathrm{a}, *}$, Hans Hoeken $^{\mathrm{b}}$ and José Sanders ${ }^{\mathrm{a}}$ \\ ${ }^{a}$ Centre for Language Studies, Radboud University Nijmegen, The Netherlands \\ ${ }^{\mathrm{b}}$ Utrecht Institute of Linguistics OTS, Utrecht University, Utrecht, The Netherlands
}

Received 26 February 2015

Accepted 11 January 2016

\begin{abstract}
.
BACKGROUND: The working environment, the nature of the work, and the characteristics of truck drivers as a social group typically pose great challenges for the truck drivers' health and health promotion activities aiming to improve it.

OBJECTIVE: The purpose was to obtain a better understanding of (a) Dutch truck drivers' perceptions of health and lifestyle themes, and (b) the challenges they experience in their pursuit of a more healthy lifestyle, as a guiding framework for the development of health interventions targeting this occupational group.

METHODS: In this qualitative study, we conducted and analyzed 20 semi-structured interviews and seven cases of participant observations with Dutch truck drivers. Grounded theory was used to analyze the data.

RESULTS: Our findings illustrate that Dutch truck drivers wish to improve their lifestyle but have unproductive associations with concepts of healthy living as well as a tendency to downplay their health risks. In addition, they experience barriers within their work and personal environment that prevent them from translating their intentions into actual lifestyle changes. CONCLUSIONS: Based on the insights derived from the interviews, we discuss recommendations for the development of more effective health promotion interventions for truck drivers.
\end{abstract}

Keywords: Truck drivers, trucking work environment, occupational health, grounded theory

\section{Introduction}

In the Netherlands, an estimated 90,000 individuals (7\% women) are employed as either short haul or long haul truck drivers [1, 2]. In general, these transport workers have a relatively lower level of education and lower socioeconomic status (SES), presumably corresponding with lower health literacy [3-5], which is defined as "the cognitive and socials skills which determine the motivation and the ability of individuals to gain access to, understand and use information

\footnotetext{
*Address for correspondence: Anniek Boeijinga, MA, Centre for Language Studies, Radboud University Nijmegen, P.O. Box 9103, 6500 HD Nijmegen, The Netherlands. Tel.: +31 024 3611475; E-mail: a.boeijinga@let.ru.nl.
}

in ways which promote and maintain good health" [6]. Like other low-SES groups, Dutch truck drivers are typically living a less healthy lifestyle, eating less vegetables and fruits, and exercising less than highSES groups [7, 8]. As a group, Dutch truck drivers have a relatively poor health and run a higher risk of serious health problems such as obesity, diabetes, high blood pressure and cholesterol levels [7].

Apart from a generally less healthy life style typically associated with a lower SES, truck drivers' working conditions pose additional threats to their health. The Netherlands, being part of the European Union, complies with the Regulation (EC) 561/2006 on EU drivers' hours, which stipulates that the total accumulated daily driving time may not exceed 9 
hours, and that the total accumulated daily duty time may not exceed 13 hours. These constraints are, of course, intended to protect truck drivers, but cause many unplanned breaks at inconvenient moments and unwanted delays for Dutch truck drivers due to the dense and unpredictable course of traffic in The Netherlands, resulting in relatively irregular and nonstandard working hours [9].

Results from the European Working Conditions Survey have shown many unfavorable scores for EU truck drivers in general: Prolonged periods of driving/sitting, whole-body vibration, tiring or painful positions, long working hours (on average more than 48 hours a week), and nonstandard working hours (night and evening work, weekend work and more than 10 hours work per day) bring about an increased risk of overweight, lower back pain, chronic fatigue, cardiovascular and respiratory diseases, and work related stress [10]. To manage working constraints, truck drivers have developed a variety of strategies. Snyder [11] describes how truck drivers develop an understanding of their body rhythms -sleep, attention, motivation, and adrenaline- and learn to manipulate these rhythms in order to link clock time to freight time. Fournier, Montreuil and Brun [12] found that experienced truck drivers engage in managing psycho-physical transformations (such as hunger, fear, sleepiness, boredom, irritation, etc.) and dynamic work planning to deal with working constraints. Truck drivers' strategies for dealing with fatigue involve pulling over when tired, drinking caffeine beverages, sleeping regular hours, and a good night's sleep before departure [13]. That is, the trucking occupation requires a professional knowledge of one's body's capacity for attention, alertness, and fatigue and thus a "professionalization" of truck drivers' bodies [11].

In addition to working conditions, the working environment places truck drivers also at high risk for poor health outcomes [14]. Apostolopoulos et al. $[15,16]$ show for US truck drivers how the truckers' work setting (i.e., trucking terminals, warehouses, truck stops, highway rest areas, and truck cabs) negatively affects their eating patterns because of a lack of healthy food options as well as limits their physical and recreational activity behaviors because of the absence of exercising devices at work settings. As a result, truck drivers have few opportunities to eat healthy meals and to take exercise breaks when on the road $[16,10]$. The work settings of Dutch truck drivers appear to be quite similar to those of US truck drivers: $37 \%$ of the Dutch truck drivers reported irreg- ular eating patterns and another $26 \%$ reported eating at unfixed times, but at regular intervals. More than half $(56 \%)$ indicated that it is not possible to do exercises or workouts during work time and/or at work settings [17].

Given the truck drivers' characteristics (i.e., lower SES and lower health literacy) as well as the nature of their work and working environment, they can be considered a high risk, underserved occupational group. Initiatives that empower them to lead a more healthy life are needed, not only from the perspective of the individual truck driver's health but also from an economical one. The Netherlands face a serious truck driver shortage in the near future [18]. Given that fewer young adults aspire to become a truck driver, it is therefore important that the current truck drivers stay healthy and keep working to an older age. Both the individual well-being and the economic factor have led to various health promotion activities targeting Dutch truck drivers, such as the large scale Dutch campaign "Fit op de Rit" (Fit for the road; campaign period 2006-2007), the launch of the "EHBO-toolbox" (First aid toolbox for relaxation; campaign period 2010-2011), and the distribution of leaflets on diet, exercise, posture, fatigue, stress, and health and safety (from 2010 onwards). These initiatives have not been very successful: At present, $19 \%$ of the Dutch truck drivers are obese $\left(\mathrm{BMI}>30 \mathrm{~kg} / \mathrm{m}^{2}\right)$ compared to $10 \%$ of the overall workforce, and another $49 \%$ of the Dutch truck drivers are overweight (BMI range $25-30 \mathrm{~kg} / \mathrm{m}^{2}$ ) [17]. These are alarming figures, considering that truck drivers with higher BMI-scores are significantly more and longer absent from work than truck drivers with lower BMI-scores [17]. Moreover, it raises the question whether the current intervention strategies targeting truck drivers are sufficiently tailored to the perceptions and needs of this particular target group. Whereas previous studies have extensively examined truck drivers' level of access to healthcare service [e.g. 14, 19, 20], truck drivers' health outcomes [e.g. 21-24], truck driver fatigue [e.g. 13, 25, 26], and road safety [e.g. 27-29], little is known about truck drivers' personal perceptions of health and lifestyle themes. Charting truck drivers' perspectives on health is crucial for the development of (more) effective health intervention approaches. Therefore, we conducted a qualitative study among Dutch truck drivers, with the aim to obtain a better understanding of (a) Dutch truck drivers' perceptions and verbalizations of health and lifestyle themes, including truck drivers' experience with and appreciation of previous health 
initiatives targeting them, and (b) the challenges and barriers experienced by Dutch truck drivers on their road to healthy lifestyle changes, including successful coping strategies to overcome these barriers.

\section{Methods}

To answer our research questions, we conducted 20 semi-structured face-to-face interviews as well as seven cases of participant observation.

\subsection{Participants and procedure}

Once ethical approval was obtained from the Ethics Assessment Committee, we invited truck drivers to participate in our study. Recruitment took place along three routes: (a) via ArboNed (one of the largest Dutch occupational health and safety organizations), (b) via transport companies, and (c) via the researchers' own social network. The different routes of recruiting resulted in a heterogeneous sample of truck drivers. The majority of the interviewees were male (19 out of 20), had a partner (15), and were short haul drivers (13). This distribution of short versus long haul drivers is similar to the distribution in the population [30]. The sample also covered a wide range of age (20-70) and years of trucking experience (1-50 years) (see Appendix A for an overview of the participants' demographics).

At the start of the interview, we informed each participant in terms of procedure. We explained that questions would be asked about working and living as a truck driver, stressing that there were no wrong answers, and assuring anonymity and the right to stop at any time without explanation. As the concept 'health' may evoke rather negative associations among low-SES target groups [31, 32], we avoided this and related expressions at the beginning of the interviews. We used semi-structured questions, ranging from general inquiries about experiences and events associated with being a truck driver (e.g. work hours, working conditions, and social and physical aspects of the job), to more specific questions about, for example, satisfaction with one's own physical condition, current eating and exercise behavior, and previous attempts to improve one's condition. Since truck drivers might vary in the way and degrees of interest in health depending on their different roles -e.g., as a truck driver, father, husband, and so forthwe included themes such as spending of leisure time, and home/family situation as interview topics in order to ensure that both the work environment and the personal environment were addressed. Towards the end of each interview, the participants' particular needs with respect to health and healthy living, as well as their appreciation of previous health promotion activities were addressed. At the end of the interview, we debriefed each participant about the nature and purpose of the research. All interviews were audio recorded and transcribed.

Interviews were conducted until the point of saturation was achieved, that is, the point where we were sufficiently convinced that properties and dimensions of the targeted concepts and conceptual relationships were fully described in their complexity and variation [cf. 33]. In our study, saturation was achieved after 20 interviews. At this point, additional interviews only confirmed our obtained insights rather than change or add to them.

In addition to the interviews, we conducted seven cases of participant observation. One of the researchers rode along with three Dutch short haul truckers (the average observation period was 12 $(+/-2)$ hours $)$, and visited two road restaurants, one transport company, and, finally, an annual national truckers festival. All observations were recorded in the form of field notes. The participant observations not only allowed for a more thorough understanding of Dutch truck drivers' experiences and their job requirements, but also of the truck drivers' social network, that is, colleague truck drivers, clients, planners, and/or family members. The observations provided background and context and, as such, were useful in the interpretation of the interview data.

\subsection{Data analysis}

The data were analyzed employing the coding principles of the grounded theory approach [34]. In this approach, data analysis is divided into three phases: open coding, axial coding, and selective coding [35]. In the open coding phase, we examined the data word by word and line by line to identify important naming categories. This resulted in six main coding categories reflecting the focus of the research: health perception, perceived barriers, coping strategies, appreciation of previous health initiatives, work setting, and private setting. In the axial coding phase, we related and compared the naming categories to one another to reveal patterns and overarching concepts, which lifted the coding to a more abstract level. Finally, in the phase of selective coding, we identified core categories which were then systematically 
related to the other (sub)categories, resulting in our insights and figures. By actively searching for similar and deviant cases, the detected patterns and relationships were checked against the data. Although described as a linear process, the coding and theorizing was in fact an iterative, dynamic process in which coding phases are interwoven, moving back and forth between the three phases.

By using a grounded theory approach we were able to develop -via a combination of inductive and deductive reasoning-insights and figures that, together, provide a thorough understanding of Dutch truck drivers' road to healthy lifestyle changes and a detailed description of the barriers perceived by Dutch truck drivers' in their attempt to adopt healthier eating and/or exercise patterns, including successful strategies to overcome these barriers. To warrant validity and reliability, we organized a meeting where we shared our preliminary findings with both applied researchers in the field of health communication and experts within the Dutch sector of transport and logistics. During this meeting, the conceptualizations and insights were confirmed and nuanced, resulting in the integrated findings presented in the next section.

\section{Results}

The findings presented in this section are illustrated by figures and interview quotes, which, for this occasion, were translated from Dutch to English ${ }^{1}$. Caution was taken to preserve the individual truck drivers' modes of expression, which resulted for some quotes in characteristic language.

\subsection{Truck drivers' view on the determinants of well-being}

All interviewees agreed on the importance of one's health for their well-being. Its importance was considered obvious, sometimes even too obvious to discuss.

Itee no. 1: Listen, it's really simple. If you're not healthy, you got no life. Weird question, health is simply the most important thing there is.

However, health was not considered the only determinant of well-being. Many pointed out that enjoying life is important as well, given that "you only live

\footnotetext{
${ }^{1}$ The original quotes in Dutch can be obtained from the corresponding author of this article.
}

once". Some truck drivers referred to the types of behavior that make life for them more enjoyable, such as smoking and drinking alcohol, as a "bad habit" or a "sin". They explicitly acknowledged that these activities were at odds with good health. After claiming "health is simply the most important thing there is", the very same truck driver explained later on in the interview:

Itee no. 1: Yeah, you must have a, everyone must have something that isn't good [a bad habit]. If we all have to live by what's right, well. That's what I told them in the hospital as well. I said: "If I have to live by what's right, then I'll get two sprouts, three green beans, two leafs of lettuce, and a glass of water." And that's supposed to be healthy. Well, that's not for me. In the evening, I sometimes get myself some spare ribs. And then those spare ribs will go into the oven over there. And then I'll take a jar of garlic sauce together with some beers and then I sit and wolf it down, heaven. Completely at ease. Oh well, and then I'll reach the age of 70 instead of 75 .

These fragments exemplify how healthy life is contrasted with enjoying life: Healthy eating behavior is framed as desirable but difficult and unattractive ("... two leafs of lettuce and a glass of water"), whereas unhealthy habits are framed as sinful but seductive and appealing.

Individual differences with respect to how to balance a healthy life and an enjoyable one were remarkable. For some interviewees, the importance of health outweighed the importance of enjoyment, whereas for others both were equally important. Note that a number of interviewees explicitly valued a joyful life more than a healthy life, as the following excerpt exemplifies:

Itee no.17: No, I don't pay a lot of attention to health. I'm like: I live today and what tomorrow brings, well, yeah, it [tomorrow] might just be the end. Well, you hear it everywhere these days. Cancer here, cancer there, cancer so and so. So I try, so to say, to really enjoy this week.

It appears that truck drivers perceived their wellbeing as determined by health status and enjoyment. Therefore, their well-being is supported by two factors that they perceive as being at odds with each other which, unavoidably, creates tension (see Fig. 1). 


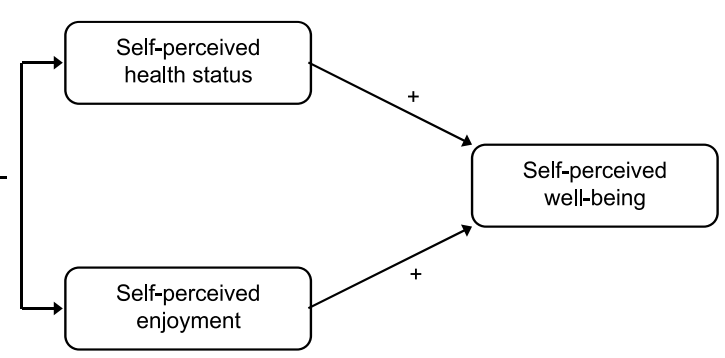

Fig. 1. Dutch truck drivers' conceptualization of their well-being.

\subsection{Truck drivers' perception of their health status}

Truck drivers were asked about their perception of their current health status. Overweight was one of the problems commonly noted by the interviewees. "Over the years, the kilos creep on", as stated by a truck driver. Some of the elder interviewees had gained several tens of kilos over the years on the job. Overweight is related to, amongst others, cardiovascular diseases. Participants narrated about heart attacks, involving either themselves or one of their colleagues. Other health problems were mainly related to back, neck, knee and shoulder pains, again caused by overweight and/or worn vertebrae or physical workload.

Aside from physical health conditions, mental health issues also proved important to the participants' well-being. Nearly all interviewees reported (chronic) fatigue as a result of their challenging and stressful work setting. Stress was the result of time pressure (over-optimistic planning) and frustrating factors beyond the truck driver's control, such as waiting times at clients, traffic jams, and the erratic behavior of other road users. As exemplified in the excerpt below, the truck driving profession demands high levels of alertness:

Itee no. 9: Look, I think that truck drivers, when they say that truck driving is an easy job, then I don't agree. Mentally it's a quite demanding job, because you have to constantly watch. You need to, constantly need to anticipate the behavior of other road users: what will they do next? Because, like last week, one truck driver almost got a ticket, he was telling me. He had, according to the policeman, he'd misjudged the situation. There was one [other road user] who cut him off, who braked to take the road exit. So, as a truck driver, you need to see all of that coming. ... Well, I think that's all a bit over exaggerated, but, yeah, it's all mentally, well, you have to constantly look in your mirrors. Much more than in a regular car. You [as a truck driver] drive a vehicle that's longer, heavier, you name it.

It is noteworthy that older participants mainly brought up physical health issues, whereas younger ones mainly emphasized the mental health aspects related to the job.

When talking about their health status, interviewees consistently compared their own health to that of other truck drivers who, in their perception, were in a worse condition. This process of comparing oneself to others who are supposedly doing worse, can be conceived as a case of downward social comparison [cf. 36]. Below is an example of a response to the question of whether the interviewee is satisfied with his physical condition.

Itee no. 1: What more could I want? I'm 56, I still work every day. I do have knee pains. Oh well, there are people who are doing much worse.

Downward social comparison enables truck drivers to evaluate their current health status as relatively good as a result of which they do not feel the need the change their lifestyle. Only when health problems can no longer be ignored, changing to a more healthy lifestyle is considered.

Itee no. 8: With some, with most the message won't stick. If they don't suffer from anything, it's that simple. If you smoke like a chimney and you do not suffer from anything, then you just keep on smoking. And there are many of those. Many people only start or quit something or change something if they suffer from something. That's just how it works.

Several of the elder participants labeled the age of 50 as a turning point; around that age, symptoms, such as physical pains, reduced fitness, illness, and ailments, could no longer be ignored or downplayed.

Itee no. 8: Most find it all, well, they find it not so important. Until they, well. I also know a mate of mine, who always had much more than me, never enough, never enough. And, well, he had to take blood thinners. 44 years old, he has to take blood thinners for the rest of his life. Well and that's, that's all... Also smoking regularly, drinking coffee. And some of us can take that, they'll turn 80 doing so, but most of us can't. That's just... For most of us reality will catch up. And most of us 


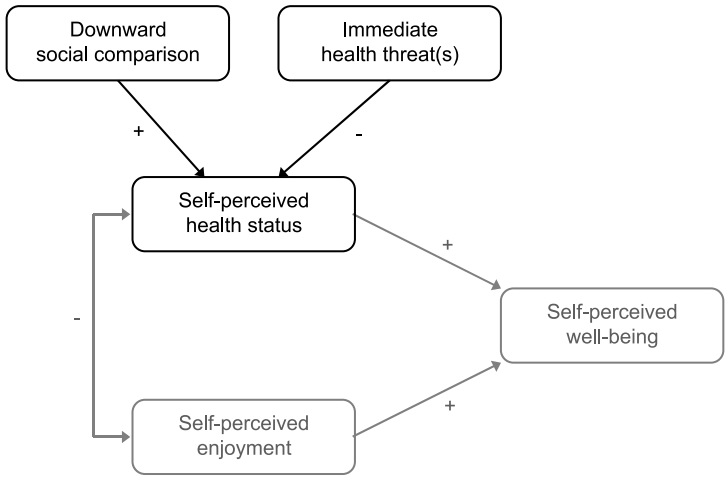

Fig. 2. Factors affecting Dutch truck drivers' self-perceived health status.

don't realize that. Well, if they're about 50 years old, then they start to realize.

The truck drivers' perception of their current health status is thus a delicate balance between feared and experienced health problems and the extent to which these symptoms and threats can be ignored and downplayed by means of downward social comparison (see Fig. 2).

\subsection{Truck drivers' road to healthy lifestyle changes}

The majority of the interviewed truck drivers indicated that they would like to eat healthier and/or to exercise more. Especially interviewees aged 50 years or more, referred to signs of physical deterioration as the incentive to (finally) put their intentions to live more healthy into action. Given their challenging working environment and the nature of their work, we were interested in how the truck drivers went about in trying to live a more healthy life. Participants were asked about any previous attempts to improve their lifestyle and whether they had experienced any barriers or setbacks.

The interviewees reported considering themselves responsible for their own health. This view was reflected in their answers to inquiries about adopting a healthy lifestyle: e.g., "it's a matter of will power", "it is a matter of choice", "it's your own choice", "you can make it as unhealthy as you want", and "your health is in your own hands". This perception of control seemed specifically to apply to eating behavior; it was mentioned considerably less often in combination with patterns of physical exercise.

Although the participants generally stated that eating healthier depends on discipline and willpower, they also referred to the challenges and limitations they experience as caused by their work setting (e.g., nonstandard working hours).

Itee no. 19: So and yeah, it wasn't a real attempt to lose weight, well I did eat less and stuff like that, right. I mean, eating less, eating less unhealthy food, I mean.

Iter: And is that doable?

Itee no. 19: Yeah, it's in your own hands. It's doable, but if you don't have time to buy some fresh stuff at the normal [supermarket] hours and no time to do any cooking at home, then you can fill in the story and finish it yourself.

With respect to physical exercise, participants mainly referred to external factors determining their behavioral choices. Lack of time and (sport) facilities were attributed to the nature of their work and their working environment.

In conclusion, for the truck drivers in our study the road to a healthier lifestyle is one with various barriers and obstacles that, by means of successful strategies, need to be overcome before they are able to act on their intention to eat more healthy and/or exercise more (see Fig. 3). In the next section, the perceived barriers are discussed.

\subsection{Perceived barriers and strategies to overcome these barriers}

Table 1 provides an overview of the barriers perceived by Dutch truck drivers. It is striking that a large number can be attributed to a lack of regular working hours, especially for long haul truck drivers. According to the interviewees, their irregular and nonstandard working hours result in a lack of (a) routine, (b) time, (c) energy, and (d) motivation to develop and persist in healthy dietary and/or exercise patterns.

The tight schedules, irregular hours, and challenging deadlines that characterize the transport sector, restrict the opportunities during working hours to adhere to fixed lunch breaks or exercise breaks. Because of the long working hours, most truck drivers end their workday rather late-causing a reported lack of time for grocery shopping, cooking, exercising or going to the gym.

Itee no. 19: What else, yeah, doing sports, right now I don't have time for that. When I come home, I'm just exhausted and then you've to make some food, take care of your cat and then quickly 


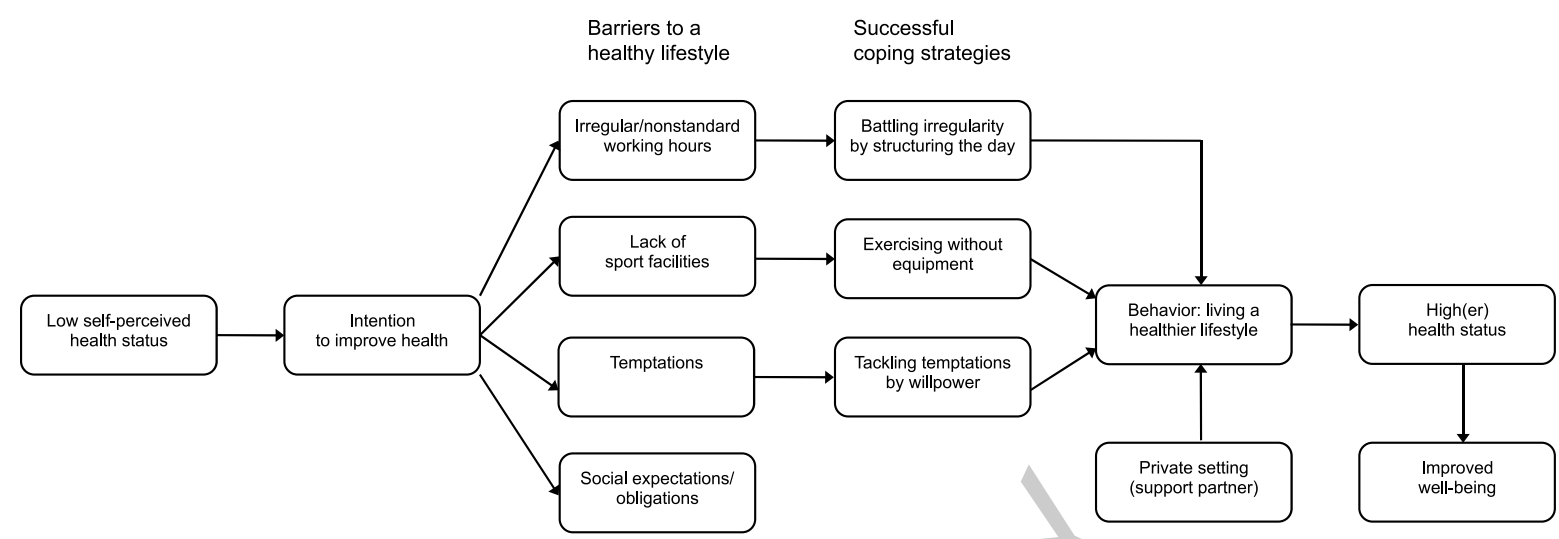

Fig. 3. Dutch truck drivers' road to healthier eating and/or exercise behaviors.

Table 1

Barriers Dutch truck drivers face in adopting healthier eating and/or exercise behaviors

\begin{tabular}{|c|c|c|}
\hline Type of behaviors & Perceived barriers within the work environment & Perceived barriers within the personal environment \\
\hline Eating + exercise & $\begin{array}{l}\text { Irregular/nonstandard working hours } \\
\text { Lack of routine } \\
\text { Lack of time } \\
\text { Lack of energy } \\
\text { Lack of motivation }\end{array}$ & $\begin{array}{l}\text { Social expectations/obligations } \\
\text { Expectations and/or obligations within the private } \\
\text { setting (e.g. spending time with family) }\end{array}$ \\
\hline Eating & $\begin{array}{l}\text { Temptations } \\
\text { Temptations along the road } \\
\text { Temptations within the truck (food supp }\end{array}$ & $\begin{array}{l}\text { Temptations } \\
\text { Temptation in/around house } \\
\text { Moments of 'joy' or 'sin' (e.g. during celebrations } \\
\text { and festivities) }\end{array}$ \\
\hline Exercise & $\begin{array}{l}\text { Lack of facilities } \\
\text { Lack of exercising facilities (gyms) } \\
\text { Lack of refreshing facilities (showers) }\end{array}$ & $\begin{array}{l}\text { Lack of facilities } \\
\text { Lack of exercising facilities with extended opening } \\
\text { hours }\end{array}$ \\
\hline
\end{tabular}

do some household chores and then it's already time to go to bed. So, yeah, where do I find the time?

As becomes clear from the excerpt above, the working hours also drain the truck drivers' level of energy. Nearly all of the interviewees indicated that they were "exhausted" or "out of energy" by the end of the day or week; they had no energy left to prepare a fresh, healthy meal, and/or to exercise. Some indicated that when they finally got home, they would rather watch television and spend some time with their family.

Regarding the barriers to a healthy lifestyle, participants reported various strategies they employed to cope with them. See Table 2 for an overview of the strategies presented. We will discuss first the strategies in eating behavior, then those in exercising behavior.

\subsubsection{Healthy eating strategies}

An important strategy that a majority of participants mentioned is using willpower to ignore attractive but unhealthy eating options they are confronted with in their environment.

Itee no. 11: But I'm not gonna eat sweets, because it's just so easy to grab sweets every time. Just don't bring it [candy] with you in your truck and offer resistance to the fatty snacks, meatballs and such. ... I just don't look at it [sweets and meatballs]. When it comes to this, I'm just really strict on myself. It's a matter of discipline. ... It's your own choice; you don't have to eat those hussars salads and fatty meatballs along the road.

As an alternative, nearly all the interviewees explained they bring their own lunchbox to work, stating that this is not only cheaper, but also healthier; "you decide when and what you eat". They find that this makes it easier to maintain a regular eating pattern, which, in turn, decreases the urge to snack. In addition, interviewees typically mentioned practical tips such as "do not skip breakfast" and "replace snacks with fruit". 
Table 2

Successful strategies used by Dutch truck drivers to cope with perceived barriers in adopting healthier eating and/or exercise behaviors

\begin{tabular}{|c|c|c|}
\hline Type of behaviors & Successful strategies within the work environment & $\begin{array}{l}\text { Successful strategies within the personal } \\
\text { environment }\end{array}$ \\
\hline Eating + exercise & $\begin{array}{l}\text { Battling irregularity } \\
\text { Structuring the workday } \\
\text { Eat and/or exercise at fixed times and moments (as much } \\
\text { as possible) }\end{array}$ & $\begin{array}{l}\text { Dealing with social obligations } \\
\text { - }\end{array}$ \\
\hline Eating & $\begin{array}{l}\text { Tackling temptations } \\
\text { Using self-control and willpower } \\
\text { Avoid tempting situations (e.g. fast food restaurants) } \\
\text { Do not bring any candy or snacks } \\
\text { Replace snacks with fruit } \\
\text { Eat small/regular portions } \\
\text { Preventing hunger and cravings } \\
\text { Do not skip any meals } \\
\text { Eat at fixed times and regular intervals } \\
\text { Bring your own (healthy) food and meals }\end{array}$ & $\begin{array}{l}\text { Tackling temptations } \\
\text { Using self-control and willpower } \\
\text { Eat small/regular portions } \\
\text { Compensating for moments of 'joy'/sin' } \\
\text { Engage in (more) healthy behaviors after an act or } \\
\text { day of joy/sin }\end{array}$ \\
\hline Exercise & $\begin{array}{l}\text { Exercising without equipment } \\
\text { Keeping yourself moving } \\
\text { Bike to work } \\
\text { Bring a folding bike into your truck } \\
\text { Go for a walk/bike ride during waiting times or resting } \\
\text { moments } \\
\text { Park your truck further away from the truck stop, so you } \\
\text { have to walk further }\end{array}$ & $\begin{array}{l}\text { Exercising without equipment } \\
\text { Keeping yourself moving } \\
\text { Take the stairs instead of the elevator } \\
\text { Take a walk (with the dog) } \\
\text { Do activities with family/friends (e.g. playing } \\
\text { soccer) }\end{array}$ \\
\hline
\end{tabular}

In some participants' narratives, the importance of their partner for their eating behavior became apparent. In most cases, the interviewees' female partners are in charge of the household, buy the groceries, prepare the driver's lunch box, and determine the type and portions of the meals. In such cases, the partners have a strong influence on the truck drivers' dietary patterns.

Itee no. 2: When my girlfriend is there [at the truck driver's place], she cooks. ... My girlfriend is a vegan. Well, I'm not. I just eat meat moderately. When she is with me, then I don't eat meat at all. And during the week, it's really not that bad, my meat consumption that is.

Thus, a partner may function as an additional or even controlling factor on healthy eating habits.

\subsubsection{Healthy exercising strategies}

Most participants reported barriers connected to their working conditions that prevent them from healthy exercise behavior. In addition to the lack of exercising and refreshing facilities, several participants brought up the responsibility for their truck and the load when being on the road.

Itee no. 1: Ok, I'll tell you. Let's say I'll go from here to ... that will take me one hour. I grab my bike, go for a nice ride. Summer day, 30 degrees Celsius. All sweaty and stinky back into my truck.
You see what I mean? It just doesn't work. You're not here for a workout, you're just here to work. And sometimes you'll go take a look, because you also have to keep your eye on who, how or what. You have to keep an eye. Control your equipment.

Iter: So, the whole story about exercising more, you say: "That's, yeah, that's impossible"?

Itee no. 1: It's a utopia. Of course there are truck drivers who exercise. Of course there are, but there are also people who jump off the roof.

This participant mentioned how a small minority does in fact exercise, but indicated that he himself experiences the negative consequences of the long working hours, during which he lives where he works but is not able to exercise, for in this working environment, a "homely" activity such as sports with its consequences (transpiration, having to wash yourself) is difficult to integrate. A few participants reported successfully integrating some physical activity and exercise in their working week by, for example, going to work by bike, making less use of their car (walking or biking instead), taking the stairs instead of the elevator, doing activities with family or friends, or working out in the gym. In a few cases, activities during work time were mentioned as well; for instance, going for a short walk while waiting or resting. One of the truck drivers on the long haul 
told that he always brings a folding bike so he can go cycling after work, on the condition that his truck is parked safely. Exercise patterns can also be influenced by the partner, but not always in a positive direction as becomes apparent in the next excerpt:

Itee no. 4: And then you haven't been home all week and then you say: "Bye, I'm going for a bike ride Saturday afternoon". And then she says: "You've been gone all week and now you're leaving again." Right? That just didn't work.

This quote suggests that a major barrier to health is, again, the work-home interface (see the previous excerpt), but from a different perspective: The long working hours combined with the need to protect relationship time, leave little opportunity to exercise.

In conclusion, participants experienced different barriers to healthy eating compared to healthy exercise behaviors. Healthy eating is perceived as being under one's control, but unattractive and difficult to implement because of temptations -which can be resisted by willpower. In case of exercising, participants perceived less control. The majority of the interviewees associated healthy exercising with performing sports (in the gym) or sporting behavior (biking, running). As a result, they identified sport facilities and equipment -i.e. external factors- as a precondition for their exercise behaviors. The truck drivers further reported difficulties in integrating exercise into their life, both at work and at home. The long working hours leave little time to exercise when being at home, especially if the partner wants to spend time together.

Next to the working environment, the truck drivers' personal environment can both facilitate or inhibit the implementation of a healthy lifestyle. Note that the interviewed truck drivers did not mention any concrete strategies on how to cope with the social expectations and obligations they felt from their private setting (see Fig. 3 and Table 2), which may suggest that they located these factors outside of their span of control.

\subsection{Truck drivers' thoughts on previous health communication initiatives}

A number of the interviewed truck drivers expressed their views on the representation of truckers in previous health promotion activities and in Dutch media in general; like other low-SES groups [30], the truck drivers in our study had difficulty distinguishing (objective) health campaigns from advertisements and television programs. Overall, they evaluated these expressions negatively, mostly because the truck drivers were generally portrayed in a stereotypical way, as is illustrated in the following excerpt:

Itee no. 20: Most are just normal people, with normal families. Look, there are always some of those typical truckers. A couple of years ago, a commercial was broadcasted on TV. I don't remember for what it was, but some truck drivers were shown and they were indeed just like those typical truckers. I watched it and I was really disgusted. How disgusting, we are presented like this to the whole country [the Netherlands]. That's not us, those are exceptions, but that's how we are presented to the general public, as 'the Dutch truck driver'.

The truck drivers wanted to explicitly distance themselves from these images of heavily overweight, "meatball-eating" men: When asked about the advantages of living a healthier life, the truck drivers' answers mostly involved improvements in general condition, endurance, and, specifically, appearance; namely, not looking like a typical truck driver.

Itee no. 6: That's a stereotypical truck driver, yeah. I don't wanna pat myself on the back, but I've heard that I don't look like a truck driver. Because, when I met L. [his girlfriend], she didn't believe it either.

Not only the way in which truck drivers are portrayed, but also the proposed solutions and strategies are perceived as unrealistic and inaccurate.

Itee no. 12: Some time ago I heard a ... thing on the Belgian radio. Some Belgian Minister, who was also targeting truck drivers, I believe. It was about truck drivers' health.

Iter: Ok, you're looking quite doubtful.

Itee no.12: Truck drivers are sitting too much. Well, hello. Think of something new. Now they're going to hand out apples at a parking area. Truck drivers are sitting too much. I haven't encountered many cars that you can stand in.

This excerpt shows that even when truck drivers feel personally addressed by a health promotion message, they may feel that the message is not adequately framed, because it is not realistic about possibilities to live a healthy lifestyle in their circumstances; sitting 
less would be very difficult in an essentially sedentary work environment.

In short, communication efforts targeting truck drivers appeared to backfire as the images used are considered caricatures and the solutions proposed as fake. That is, the presented quotes illustrate that previous/current health communications targeting Dutch truck drivers are perceived as not sufficiently tailored to their perceptions and needs [37].

\section{Discussion}

The aim of our study was to obtain a better understanding of Dutch truck drivers' perceptions of health and lifestyle themes as well as the challenges and barriers experienced by Dutch truck drivers in their attempts to adopt a healthier lifestyle. In general, the truck drivers regard health as very important, but also regard behaviors improving one's health as being at odds with living a pleasant life. In order not to worry about their own health, they compare their health status to that of colleagues they consider to be worse off. Changing one's lifestyle is usually the result of health problems that can no longer be ignored. Implementing lifestyle changes is experienced as difficult because of the long and irregular working hours that prohibit the development of healthy dietary and exercising routines, as well as the lack of exercising and refreshing facilities when being on the road.

Apart from the working environment, truck drivers' personal environment can also be decisive to the implementation of healthy lifestyle changes. The truck drivers' partner, if there is one, plays an important role in controlling healthy dietary habits, because the partner usually is in charge of what and how much food there is for dinner and breakfast, and often prepares the drivers' lunch box. This potentially beneficial influence does not extend to stimulating healthy exercising habits, because the wish (or demand) to spend time with one's partner and family may prohibit drivers from exercising during leisure time.

Our findings are congruent with the Health Action Process Approach (HAPA) developed by Schwarzer [38]. This model depicts the various phases a person goes through when changing his health behavior as well as the various factors that determine whether he or she will enter the next phase or not. Three groups are distinguished when it comes to healthy behavior: actors (who already perform the desired behavior), intenders (who want to perform the desired behavior but have not done so yet), and non-intenders (who have no intention to perform the behavior). Given the truck drivers' health problems described in the introduction, it appears that the vast majority are not actors. This raises the question as to whether Dutch truck drivers are intenders or non-intenders?

Non-intenders are considered to be in the motivational phase [38]. That is, they need to be motivated to change their intention. According to the HAPA model, there are three factors that determine this intention: risk perception, outcome expectancies, and action self-efficacy. The results of the interviews suggest that these factors are also at play for Dutch truck drivers. Risk perception refers to one's belief that one is at risk for a certain disease. Only when people consider themselves at risk, they will contemplate behavioral alternatives to their current lifestyle [38]. Truck drivers appear to manage their risk perception through downward social comparison up to the point where physical complaints can no longer be ignored. In addition, outcome expectancies play a role: What consequences will a change in lifestyle have? Here, the truck drivers seem to think that a more healthy lifestyle will lead to a less enjoyable life. Finally, the intention to live a more healthy life depends on the belief that one will be able to perform the recommended behavior (action self-efficacy). Truck drivers are not very confident about their chances to put their intention into action because of the long and irregular working hours, lack of facilities, and temptations when they are on the road, as well as the social expectations and obligations from their private setting.

Still, many truck drivers indicate that they would like to live a more healthy life and even repeatedly have tried to do so. This qualifies them as intenders in the HAPA model [38]. The fact that they did not succeed in adapting their lifestyle is explained in the HAPA model by problems in action or coping planning. The former refers to the problem of failing to get started. People are stuck in their old routines, keep putting off a change of behavior. The repeated references to "will power" in the interviews suggest that it takes effort to concretely plan and perform the intended actions. Coping planning refers to the activity of mentally preparing oneself for dealing with obstacles that can be encountered while aiming to perform the intended behavior. For instance, how to deal with a lack of exercise devices or healthy choices at trucking settings or how to decline an offer for a beer by friends and colleagues? The better one is prepared for overcoming such barriers, the more likely it is that one can perform the intended behavior. It must be taken into account that the barriers faced by long 
haul drivers differ from those experienced by short haul drivers. Long haul drivers, for example, are away from home for stretches of several days, drive international routes, and are more likely to work irregular working hours than short haul drivers. The latter work within the national borders and come home at night, thus having more opportunities to make their individual eating and exercising choices. As a result of these differences in work and personal constraints, successful strategies to obtain a better health may differ for these target groups.

Given our findings we recommend that health interventions targeted at Dutch truck drivers should aim to (a) make sure that they do not underestimate the health risks they run, (b) provide a realistic yet attractive image of the outcomes of a more healthy lifestyle, (c) focus on action planning (specifying "when", "where", and "how" to perform the recommended behavior) and coping planning (imagining what obstacles there might be and how to deal with them). In the case of exercising behavior, reframing 'exercise' may be another promising strategy. Truck drivers in our study, currently frame exercise as sporting behavior. Frames provide interpretive contexts that guide the interpretation and sense making of particular (health) issues and as such construct what people experience as (un)true and (im)possible [39]. Reframing exercise as 'moving'/'being physically active' offers an alternative frame that verbalizes more ecologically plausible aspects for truck drivers to act upon [40], and may lead to an enforcement of truck drivers' sense of control and self-efficacy.

Although our study was performed at the individual level, we recommend to expand the focus to an ecological level. From our results it became clear that truck drivers ascribe much of their inability to make healthy lifestyle choices to structural constraints of the work environment -especially the irregular and nonstandard working hours and the lack of exercise and refreshing facilities. These findings are in line with previous research on the environmental barriers to healthy eating and active living in the trucking industry $[15,16]$. The few studies of health promotion programs targeted at truck drivers primarily focused on changes at the individual level and this is a concern, as environmental and work organization factors are important determinants of both chronic disease outcomes and health-related behaviors in truck drivers [41].

Thus, making healthy lifestyle choices is not solely a responsibility of individual truck drivers; the trucking industry and governments are involved as well.
For health promotion strategies for truck drivers to be effective, they should incorporate a comprehensive multi-stakeholder strategy; this implies that trucking companies, insurance companies, occupational health services, the national institute of transport and logistics as well as governmental regulatory bodies should work together to collectively create a (more) healthy transportation work environment and to make commercial trucking more flexible and less exhausting, thereby facilitating more healthy lifestyle choices [4]. Such a holistic approach would not only be beneficial from the perspective of individual truck driver's health, but also from an economical perspective; a healthier work environment would potentially make a trucking job more attractive -an important feature given the predicted truck driver shortage.

\section{Conclusions}

By providing a deeper understanding of Dutch truck drivers' perceptions of health and lifestyle themes, and the challenges and barriers faced by Dutch truck drivers on the road to a healthier lifestyle, including successful strategies to overcome these barriers, the present study presents recommendations for the development of more effective health promotion interventions for this particular target group. Our findings and figures suggest three specific areas of focus to be considered in developing intervention strategies to empower truck drivers to lead a more healthy life: truck drivers' (a) risk perceptions, (b) outcome expectancies, and (c) action and coping planning strategies. Based on our findings, we advocate both realistic life style recommendations at the individual level and an ecological approach to health promotion interventions at the level of truck driving working conditions, since changing individual behaviors is easier when facilitated by changes in the work environment as a whole. Future research should be conducted to further verify our findings, in particular truck drivers' particular mindset, and to test the effectiveness of promising multi-stakeholder approaches.

\section{Acknowledgments}

The authors thank the professional drivers who generously donated time from their busy lives to this project. This study was funded by the Netherlands Organization for Scientific Research (NWO/ ZonMW); project BGRL-11-15. 


\section{Conflict of interest}

The authors have no conflict of interest to report.

\section{References}

[1] Federatie Nederlandse Vakbeweging (FNV). Eerste plan werkgelegenheid: transportsector zet in op vakmanschap [First plan for employment: Transport sector focuses on expertise]; 2013 [updated 2013; cited 2014 Jan 18]. Available from: http://www.fnvbondgenoten.nl/ mijnbranche/branches/transport_en_logistiek/nieuws/6486 56-transportsector_zet_in_op_vakmanschap/

[2] Transport en Logistiek Nederland (TLN). Transport in cijfers: Editie 2014 [Transport in figures; edition 2014]; 2014 [updated 2014 March 21; cited 2015 October 22]. Available from: http://www.tln.nl/Actueel/Algemeen/ Transport-in-cijfers-editie-2014-aspx.aspx id=D551B1 56733106E867DF2A663E244640

[3] European Foundation for the Improvement of Living and Working Conditions (EFILWC). Fact sheet: Land transport; 2008 [updated 2008; cited 2009 Dec 13]. Available from: http://www.eurofound.europa.eu/pubdocs/2008/149/en/1/ EF08149en.pdf

[4] Van der Beek A. World at work: Truck drivers. Occup Environ Med 2012;69:291-5.

[5] Twickler TB, Hoogstraaten E, Reuwer A, Singels L, Essink-Bot ML. Laaggeletterdheid en beperkte gezondheidsvaardigheden vragen om een antwoord in de zorg [Low literacy and low(er) health literacy ask for an answer from the health sector]. Nederlands Tijdschrift voor Geneeskunde 2009;153:A250.

[6] World Health Organization (WHO). Division of Health Promotion, Education and Communications. Health Education and Health Promotion Unit. Geneva: Health Promotion Glossary; 1998.

[7] Rijksinstituut voor Volksgezondheid en Milieu (RIVM). Leefstijl en arbeid in balans. Een literatuurstudie naar de invloed van leefstijlfactoren en (sub)cultuur op gezondheid, ziekteverzuim, arbeidsongeschiktheid en productiviteit [Balancing lifestyle and work. A literature review on the influence of lifestyle factors and (sub)culture in health, absenteeism, disability, and productivity]. RIVM rapport 270254001/2008; 2008.

[8] Gezond Transport. BRAVO-cijfers 2012 [The Dutch transport sector's 2012 figures on Exercise, Smoking, Alcohol, Nutrition, and Relaxation]. TON Magazine 2013;45: 34-5.

[9] Van Bogerijen I. \& Nederlands Instituut voor Sport en Bewegen (NISB). Wat beweegt vrachtwagenchauffeurs? Een kwalitatief onderzoek naar de betekenissen die vrachtwagenchauffeurs geven aan gezondheidsstimulering op het werk en de omgevingsfactoren die volgens hen van invloed zijn op hun gezondheid [What moves truck drivers? A qualitative study on the meanings that truck drivers give to health promotion in the work place and to the environmental factors that influence their health]. Utrecht: Universiteit Utrecht; 2010

[10] European Agency for Safety and Health at Work (EUOSHA). E-fact 47: Health promotion in the transport sector; 2006 [updated 2006; cited 2013 Nov 18]. Available from: https://osha.europa.eu/nl/publications/e-facts/efact 47
[11] Snyder BH. Dignity and the professionalized body: Truck driving in the age of instant gratification. The Hedgehog Review 2010;14(3):8-20.

[12] Fournier P, Montreuil S, Brun J. Fatigue management by truck drivers in real life situations: Some suggestions to improve training. Work 2007;29(3):213-24.

[13] Arnold PK, Hartley LR, Corry A, Hochstadt D, Penna F, Feyer AM. Hours of work, and perceptions of fatigue among truck drivers. Accident Analysis \& Prevention 1997;29(4):471-7.

[14] Apostolopoulos Y, Sönmez S, Shattell MM, Gonzales C, Fehrenbacher C. Health survey of U.S. long haul truck drivers: Work environment, physical health, and healthcare access. Work 2013;46:113-23.

[15] Apostolopoulos Y, Sönmez S, Shattell MM, Haldeman L, Strack R, Jones V. Barriers to truck drivers' healthy eating: Environmental influences and health promotion strategies. Journal of Workplace Behavioral Health 2011;26(2): $122-43$.

[16] Apostolopoulos Y, Shattell MM, Sönmez S, Strack R, Haldeman L, Jones V. Active living in the trucking sector: Environmental barriers and health promotion strategies. Journal of Physical Activity and Health 2012;9:259-69.

[17] Gezond Transport. Trendrapport 2013. Preventie, verzuim en duurzame inzetbaarheid in de sector transport en logistiek [Trend report 2013. Prevention, absenteeism, and sustainable employability in the Dutch transport and logistics sector]; 2013 [updated 2014; cited 2014 May 6]. Available from: http://www.stlwerkt.nl/VTL/media/MediaLibrary/Gezond\%20Transport/trendrapport-gezondtransport-eindversie-december-2013_met-omslag1.pdf

[18] Transport en Logistiek Nederland (TLN). Sector luidt noodklok over toekomstig tekort arbeidskrachten [Transport sector rings the alarm bells because of future labor shortage]; 2013b [updated 2013 May 28; cited 2014 Jan 9]. Available from: http://internettv.roc.nl/default. php?fr=nieuws\&nieuwsitem $=30686$

[19] Staško JC, Neale AV. Health care risks and access within the community of Michigan over-the-road truckers. Work 2007;29(3):205-11.

[20] Solomon AJ, Doucette JT, Garland E, McGinn T. Healthcare and the long haul: Long distance truck drivers-a medically underserved population. American Journal of Industrial Medicine 2004;46(5):463-71.

[21] Marqueze EC, Ulhôa MA, Moreno CRC. Irregular working times and metabolic disorders among truck drivers: A review. Work 2012;41(1):3718-25.

[22] Sharwood LN, Elkington J, Stevenson M, Grunstein RR, Meuleners L, Ivers RQ, Haworth N, Norton R, Wong KK. Assessing sleepiness and sleep disorders in Australian longdistance commercial vehicle drivers: Self-report versus an "at home" monitoring device. Sleep 2012;35(4):469-75.

[23] Dahl S, Kaerlev L, Jensen A, Tüchsen F, Hannerz H, Nielsen PS, Olsen J. Hospitalization for lifestyle related diseases in long haul drivers compared with other truck drivers and the working population at large. Work 2009;33(3):345-53.

[24] de Croon EM, van der Beek AJ, Blonk RWB, Frings-Dresen MHW. Job stress and psychosomatic health complaints among Dutch truck drivers: A re-evaluation of Karasek's interactive job demand-control model. Stress and Health 2000;16(2):101-7.

[25] Baas PH, Charton SG, Bastin GT. Survey of New Zealand truck driver fatigue and fitness for duty. Transportation Research Part F: Traffic Psychology and Behaviour 2000;3(4):185-93. 
[26] Mitler MM, Miller JC, Lipsitz JJ, Walsh JK, Wylie CD. The sleep of long-haul truck drivers. The New England Journal of Medicine 1997;337:755-62.

[27] Jensen A, Dahl S. Truck drivers hours-of-service regulations and occupational health. Work 2009;33(3):363-8.

[28] Häkkänen H, Summala H. Fatal traffic accidents among trailer truck drivers and accident causes as viewed by other truck drivers. Accident Analysis \& Prevention 2001;33(2):187-96.

[29] Summala H, Mikkola T. Fatal accidents among car and truck drivers: Effects of fatigue, age, and alcohol consumption. Human Factors 1994;36(2):315-26.

[30] Lingsma J, Hengstz K, Snoek-Koot E. Chauffeursgeluk in 2011 (NL/BE/FR) [Truck drivers' happiness in 2011 (NL/BE/FR)]. Amsterdam: Randstad/Motivaction, Projectnummer M 6820; 2011

[31] Heutink H, van Diemen D, Elzenga M, Kooiker S. Wat hebben mensen met een lage en hoge(re) SES zelf te zeggen over gezond leven? [What do people with a low and high(er) SES have to say about healthy living?]. Tijdschrift voor Gezondheidswetenschappen 2010;88(1):10-2.

[32] Kooiker S. Nederlanders aan het woord over gezondheid en gezond leven: Achtergrondrapport bij de VTV 2010 Van Gezond naar Beter [Dutch people on health and healthy living: Background report on VTV 2010 From healthy to better]. Bilthoven: RIVM; 2011.

[33] Sandelowski M. Theoretical saturation. In: Given LM, editors. The Sage encyclopedia of qualitative research methods. Thousand Oaks, CA: Sage; 2008. p. 876.

[34] Corbin JA, Strauss A. Basics of qualitative research: Techniques and procedures for developing grounded theory. 3rd ed. Thousand Oaks: Sage; 2008.

[35] Walker D, Myrick F. Grounded theory: An exploration of process and procedure. Qualitative Health Research 2006;16(4):547-59.

[36] Mackie H, Moore D. "Fit for the road": Log truck driver health and wellbeing. Paper presented at the 32nd Australian Transport Research Forum. Auckland, New Zealand; 2009.

[37] Boeijinga A, Hoeken JAL, Sanders JM. An analysis of health promotion materials for Dutch truck drivers: Off target and too complex? Work (accepted/in press).
[38] Schwarzer R. Modeling health behavior change: How to predict and modify the adoption and maintenance of health behaviors. Applied Psychology 2008;57(1):1-29.

[39] Goffman E. Frame analysis: An essay on the organization of experience. New York: Harper \& Row; 1974.

[40] Sallis JF, Owen N, Fisher EB. Ecological models of health behavior. In: Glanz K, Rimer B, Visnawath K, editors. Health behavior and health education: Theory, research, and practice. 4th ed. Jossey-Bass; 2008. pp. 465-85.

[41] Ng MK, Yousuf B, Bigelow PL, Van Eerd, D. Effectiveness of health promotion programmes for truck drivers: A systematic review. Health Education Journal 2015;74(3):270-86.

\section{Appendix A}

Demographics of the interviewees $(n=20)$

\begin{tabular}{lc}
\hline Characteristics & Truck drivers' $n(\%)$ \\
\hline Gender & \\
Men & $19(95)$ \\
Women & $1(5)$ \\
Age & \\
$20-30$ & $4(20)$ \\
$30-40$ & $2(10)$ \\
$40-50$ & $7(35)$ \\
$50-60$ & $5(25)$ \\
$60-70$ & $2(10)$ \\
Relationship status & \\
Partner & $15(75)$ \\
No partner & $5(25)$ \\
Type of trucking & \\
Long haul & $7(35)$ \\
Short haul & $13(65)$ \\
Years on the truck & \\
$0-10$ & $8(40)$ \\
$10-20$ & $5(25)$ \\
$20-30$ & $4(20)$ \\
$30-40$ & $2(10)$ \\
$40-50$ & $1(5)$ \\
\hline
\end{tabular}

